\title{
Notas sobre a pirataria de games no Brasil: inclusão (digital) dos pobres e resistência
}

\section{José Carlos Messias}

Doutorando; Universidade Federal do Rio de Janeiro jmessias.santos@gmail.com

\section{Resumo}

O objetivo deste trabalho não é advogar sobre a pirataria sob um ponto de vista ético. Embora se reconheça a relevância deste debate, nossa análise se focará nas questões cognitivas e de produção de subjetividade ligadas às práticas piratas da cultura gamer. Defende-se que as subjetividades envolvidas na pirataria de games põem em movimento redes de sociabilidade, processos de autoformação e tutoria, manipulação de dispositivos técnicos complexos, além do estímulo a produção criativa e livre. O relato desta investigação em andamento se debruça sobre comunidades virtuais do site de relacionamento Orkut e sua comunidade Brazukas.

\section{Palavras-chave}

Entretenimento. Pirataria. Resistência. Games.

\section{Introdução}

Quando o assunto é pirataria, uma das primeiras associações feitas no imaginário coletivo é a do ambulante ilegal, o popular camelô, vendendo um CD ou DVD pirata numa esquina. Propagadas pela mídia, pelo setor privado, órgãos governamentais e instituições civis, essas representações falam em precariedade, baixa qualidade, mau funcionamento, prejuízo material em longo prazo e, mais recentemente, crime ${ }^{1}$. Associam-se os produtos piratas do camelô ao crime organizado da mesma forma que à TV por assinatura clandestina e ao monopólio da distribuição de gás de cozinha.

\footnotetext{
${ }^{1} \mathrm{O}$ site Brasil Escola, página dedicada à educação hospedada no portal R7, que transformou o termo em verbete e em sua definição de pirataria, junta essas alegações, embora não cite nenhuma fonte. Disponível em: <http://www.brasilescola.com/curiosidades/pirataria.htm>. Acesso em: 4 ago. 2013.
} 
Reforça-se o discurso da ilegalidade - de se estar sendo cúmplice de um crime -, ou mesmo o do fim (ou escassez) das produções originais em decorrência do suposto alto prejuízo dos grandes conglomerados de mídia responsáveis por boa parte do mercado audiovisual, fonográfico, editorial etc. Veiculados nos intervalos comerciais da programação televisiva ou mesmo antes da exibição dos filmes no cinema, vídeos trabalham a questão do empenho dos artistas e demais funcionários empregados na produção de uma obra (de ordem imaterial), assim como o reflexo da pirataria na remuneração dos mesmos².

Neste contexto, os atos de pirataria que serão tratados nesta análise exploratória abordam a questão sob outro viés. Debruçando-se sobre a questão do entretenimento de massa, especificamente os videogames, reivindica-se seu papel como campo de lutas e expressão de subjetividade - mesmo se tratando de produtos originalmente desenvolvidos para exploração pelo Capital. Sem, no entanto, priorizar um tipo de pirataria sobre o outro, abordaremos os hábitos do consumidor-pirata individual ${ }^{3}$ que recorre a sites de download e outros grupos mais centralizados e hierárquicos. A manipulação de arquivos digitais que será tratada se realiza em comunidades virtuais de sites de relacionamento, principalmente o Orkut e sua comunidade "Brazukas".

\section{Informatização}

A popularização em larga escala do uso de computadores e da internet, o que poderia se entender, grosso modo, como "inclusão digital", está na agenda de qualquer país preocupado com a questão do desenvolvimento ${ }^{4}$. Não caracterizando necessariamente uma "obsessão desenvolvimentista”, a alfabetização digital passa mais pela questão da qualidade de vida, do acesso à informação e das necessidades básicas do indivíduo.

Em contrapartida, Negri e Hardt (2010) afirmam que, na chamada Era da Informatização, o Capital demanda certa "instrumentalização tecnológica" como parte do processo de produção. Eles situam essa informatização dentro de um cenário de transições

\footnotetext{
2 No vídeo encomendado pelo Ministério da Justiça a uma agência de publicidade, a inventividade do brasileiro (sua originalidade) é associada à compra de produtos originais. Preocupando-se sempre em demonstrar o prejuízo à cadeia produtiva, especialmente aos cargos de remuneração mais baixa. Disponível em: < http://youtu.be/hEFOjlrGjBA>. _Acesso em: 17 maio 2014.

${ }^{3}$ Em vídeo produzido pela equipe do filme Tropa de Elite 2 (José Padilha, 2010), o ex-policial Rodrigo Pimentel, um dos roteiristas do filme e atualmente comentarista em telejornais da Rede Globo, aparece fazendo um apelo à população para que não pirateie o filme. Ao contrário de outras campanhas do tipo, ele se refere especificamente ao download direto da obra pela internet. Ele também divulga um blog onde as pessoas poderiam denunciar os links postados. Disponível em <http://youtu.be/22hhm3ZRU-A>. Acesso em: 17 maio 2014.

${ }^{4}$ No Brasil, um dos programas que lidam com esta questão é o Programa Um Computador por Aluno (UCA) que faz parte do Programa Nacional de Tecnologia Educacional (ProInfo). Disponível em: <http://www.uca.gov.br/institucional/projeto.jsp>. Acesso em: 2 fev. 2014.
} 
econômicas no qual um paradigma "maquínico" e laboral dá lugar a outro na medida em que este passa a melhor emular as condições de possibilidade de seu surgimento (e ativação) presentes naquela sociedade. Da mesma forma que a industrialização serviu a Modernidade, e de certa maneira a representou, a informatização seria um estágio contemporâneo em que os computadores e a circulação de informação respondem às demandas do mercado e da produção. Para os pensadores:

O computador se apresenta, em comparação, como a ferramenta universal, ou melhor, como a ferramenta central, pela qual deve passar toda e qualquer atividade. Mediante a informatização da produção, portanto, o trabalho tende a posição de trabalho abstrato. (NEGRI; HARDT, 2010, p. 313).

Isto significa dizer que a mobilidade dos indivíduos nessa pós-modernidade informatizada depende cada vez mais de seu grau de aptidão computacional, além, claro, do próprio processamento de informação e da oferta de serviços. Neste contexto, por mobilidade se entende a forma que indivíduos têm de trafegar pelo tecido social - se capacitando cognitiva, cultural e socialmente no processo - de maneira a continuar atendendo às demandas dos meios de produção numa determinada sociedade, em suma, se mantendo produtivos. Para os autores:

0 uso cada vez mais amplo de computadores tende progressivamente a redefinir as práticas e relações de produção, justamente com todas as práticas e relações sociais. A familiaridade e a facilidade com a tecnologia de computação estão se tornando, cada vez mais, uma qualificação primária geral para o trabalho nos países dominantes. (NEGRI; HARDT, 2010, p. 311-312).

Este cenário não se resume ao universo do trabalho, enviesando-se para todas as esferas da atividade humana. Não é à toa que a informatização é tratada por Negri e Hardt como uma das principais facetas do que eles denominam produção biopolítica. Esta concepção, apresentada no livro Império, designa “[...] a produção da própria vida social, na qual o econômico, o político e o cultural cada vez mais se sobrepõem e se completam um ao outro". (NEGRI; HARDT, 2010, p. 13).

Nesta obra, os autores conceberam uma apropriação da teoria marxista que também leva em consideração os conceitos de biopoder e biopolítica inicialmente trabalhados por Michel Foucault (1999). 0 pensador estava interessado nas implicações biológicas do poder, por assim dizer, mostrando como ele se manifesta diretamente nos corpos, a anátomopolítica, e como ele gere os agrupamentos populacionais, a biopolítica das populações. É justamente esse componente preliminar, o prefixo bios - a palavra grega para vida -, que 
possibilita a compreensão da extensão e dos meandros dos métodos de sujeição a partir da instituição da disciplina (da norma) como parâmetro do poder na obra de Foucault. Daí Deleuze afirmar - ao se debruçar sobre a questão - que, "[...] quando o diagrama de poder abandona o modelo de soberania para fornecer um modelo disciplinar, quando ele se torna 'biopoder', 'biopolítica' das populações, responsabilidade e gesto da vida, é a vida que surge como novo objeto do poder". (DELEUZE, 2005, p. 98). Ou seja, os métodos de sujeição se tornam cada vez mais sutis e, ao mesmo tempo, mais enfáticos.

É justamente a noção de Controle do filósofo que seria, grosso modo, a interiorização da norma (disciplina), que serviu de base para Negri e Hardt (2010) em suas próprias considerações a respeito do poder e, em especial, dos métodos de produção na contemporaneidade. Segundo eles, "O biopoder situa-se acima da sociedade, transcendente, como uma autoridade soberana, e impõe a sua ordem. A produção biopolítica, em contraste, é imanente à sociedade, criando relações e formas sociais através de formas colaborativas de trabalho". (NEGRI; HARDT, 2010, p. 135). A produção biopolítica diz respeito ao mundo do trabalho, ou melhor, à junção de trabalho e vida. Vida no sentido não só de relações sociais e capacitação técnica, mas da produção de afetos e de sua incorporação aos métodos de produção. Essas seriam algumas das características do trabalho dito imaterial.

Portanto, não se trata em absoluto de reinventar as relações de trabalho, mas de delinear as diferentes formas pelas quais o trabalho é explorado. 0 trabalho imaterial, dentro da lógica da informatização, por exemplo, reconfigura não só as capacitações intelectual e técnica, mas também a relação de tempo, de afetividades e sociabilidades. Diferente da linha de montagem, que exigia do operário o máximo de suas habilidades cognitivas durante sua estada na fábrica, a lógica imaterial tenta abarcar ainda mais aspectos da vida, de forma a compor a máquina de exploração suprema. Neste paradigma em que não há uma diferenciação clara entre o tempo do trabalho e o do lazer, a informatização pode nos ajudar a compreender o surgimento de atividades de resistência também dentro da esfera tecnológica - nesse caso, não necessariamente respostas à produção biopolítica, mas atos de insurgência que, em sua gênese autopoiética, se constituem como diferença. Uma vez que este novo trabalhador - não mais o clássico 
proletário, mas todo indivíduo dentro do Império $^{5}$-, é cooptado a operar num ambiente computacional/informatizado, seja profissionalmente ou por lazer, não é de se espantar que esse arcabouço construído seja utilizado para a expressão da subjetividade.

\section{Instrumentalização x alfabetização}

Pensando nesse universo de capacitação e lutas, acredita-se que seja possível aferir qualitativamente essa relação entre homem e máquina (vista enquanto aparato e técnica). Como foi dito, a instrumentalização digital pode ser encarada como um dos desdobramentos de uma necessidade de mobilidade dentro do Império. Fenômeno já abordado por Negri e Hardt (2010), o mercado faz com que a empregabilidade esteja condicionada à formação contínua e, no campo tecnológico, essa relação se traduz por uma ligação praticamente simbiótica com o tecnológico. De acordo com eles, “[...] máquinas interativas e cibernéticas tornaram-se uma nova prótese integrada a nossos corpos e mentes, sendo uma lente pela qual redefinimos nossos corpos e mentes". (NEGRI; HARDT, 2010, p. 312).

Para esta pesquisa, contudo, este seria um modelo de formação que permite um domínio de certa maneira limitado dos aparatos e dispositivos digitais. Essa limitação, no entanto, seria menos de ordem técnica ou capacitiva do que ética, comercial e criativa. "Castrados" pelas restrições impostas pela indústria e pelo governo - como leis de direito autoral e proteções anticópia, manipulação e edição de toda sorte - usuários são impedidos de desenvolver seu potencial subjetivo/transformador sob pena de serem taxados de hackers, piratas, indivíduos cujas atribuições estariam à margem do establishment e, em muitos casos, contra a lei. Um contrassenso, uma vez que o entretenimento, dentro do paradigma digital, mas não restrito a ele, tem como uma de suas principais características a personalização dos produtos culturais. Algo presente na ideia de cibertextos e atividade ergódica, na chamada cultura da participação ou em demais abordagens que privilegiam a cultura fã, a produção Pro-Am (profissional-amador), a perfomance, entre outros exemplos (AARSETH, 1997; HENNION, 2001; JENKINS, 2006; JOHNSON, 2012; KEEN, 2007; STEINKUEHLER; JOHNSON, 2009).

\footnotetext{
${ }^{5}$ Dentro da proposta dos autores, a antiga questão marxista da luta de classes centrada na figura do proletário, o trabalhador assalariado, precisa ser substituída pela questão do pobre e da Multidão. Dessa forma, Negri e Hardt incluem no debate outros grupos e atores que se mostram fundamentais, sobretudo a partir de 1968, na chamada luta contra-hegemônica e que estão propensos aos mesmos processos de assujeitamento que o trabalhador fabril. Desloca-se, assim, a ideia de pobre de um ponto de vista socioeconômico para a busca de empodeiramento frente ao que eles chamam de Império, a configuração do Poder na contemporaneidade. Tem-se, então, a multidão. Nas palavras deles, “[...] toda multidão é produtiva e toda ela é pobre". (NEGRI; HARDT, 2005, p. 182).
} 
Desta forma, defende-se que aqueles que conseguem burlar essas restrições técnicas e legais, seguindo justamente aquilo que lhes foi apresentado pelo capital (a personalização ou customização de conteúdo como suprassumo da experiência do entretenimento), abrem portas para a criação de novas formas de insurgência dentro do Império. Da mesma forma que a produção biopolítica marcaria a utilização de certa conexão maquínica para fins do capital, os desejos e afetos diversos dos quais são dotados o humano reorganizam e recodificam essa capacitação tecnológica, gerando, assim, uma verdadeira alfabetização tecnológica ou letramento digital. Essa alfabetização, ao contrário da ideia de instrumentalização, promoveria uma movimentação mais fluida pela rede, saindo do campo da mobilidade e passando ao da mobilização.

[...] a produção biopolítica da multidão tende a mobilizar o que compartilha em comum e o que produz em comum contra o poder imperial do capital global. Com o tempo, desenvolvendo sua forma produtiva baseada no comum, a multidão pode mover-se pelo Império e sair do outro lado, para se expressar autonomamente e governar a si mesma. (NEGRI; HARDT, 2005, p. 142).

É possível observar como, mesmo imerso numa perspectiva de exploração do trabalho imaterial, o corpo se recusa a participar dessa forma de produção, encontrando brechas e produzindo novas subjetividades no processo. Essa dupla lógica do trabalho imaterial faz dele um campo dinâmico (e até instável) de lutas, no qual a todo tempo as relações de poder se entrelaçam em meio à ação dos afetos que produzem recusas e resistências.

\section{Cognição e games}

As ciências cognitivas contemporâneas têm se debruçado sobre a relação do homem com os objetos técnicos. Áreas como robótica, psicologia cognitiva, biologia evolutiva e neurociência, entre outras, produzem saberes que versam sobre as interconexões entre mente, corpo e o ambiente externo (demais indivíduos e objetos). Passando pela concepção platônica da cognição como correlata ao pensamento até noções mais arrojadas, como os primeiros estudos sobre inteligência artificial e os "modelos computacionais da mente", o conceito de cognição ganhou diversos vieses e se tornou, assim, uma ciência multidisciplinar. Deste modo, a abordagem que será empregada neste artigo privilegia as práticas de entretenimento como campo de investigação de possíveis implicações cognitivas, uma noção adquirida a partir de Regis $(2008,2009)$. Utilizando duas das cinco 
categorias de análise desenvolvidas pela autora, espera-se mapear habilidades cognitivas específicas demandadas dos usuários em suas atividades piratas ligadas a games. A primeira delas seria a criatividade, que:

[...] se dedica às habilidades que estimulam a criação e participação nas atividades colaborativas na rede [...] o estímulo à intervenção nos produtos, por parte dos usuários, seja pela construção de obras inéditas ou pela criação por meio de mixagens [...]. Essa categoria envolve a construção social de conhecimento por meio dos recursos de blogs, redes $\mathrm{P} 2 \mathrm{P}$ e redes de relacionamento. (REGIS, 2008, p. 35, grifo nosso).

Enquanto isso, pensando os aspectos coletivos da experiência com as Tecnologias de Informação e Comunicação (TIC), chega-se a uma noção chamada sociabilidade. De acordo com Regis, ela:

[...] se relaciona ao modo como as tecnologias digitais, ao favorecer a produção de conteúdo (individual e coletiva), estimulam a formação de comunidades de gosto, parcerias, listas de discussão e blogs, incentivam que o indivíduo esquadrinhe as diversas mídias em busca da informação desejada e engendram um processo de colaboração/parceria entre indivíduos que se reúnem em comunidades virtuais, listas de discussão, blogs para buscar e produzir e partilhar informações adicionais sobre seus produtos culturais favoritos. (REGIS, 2009, p. 7, grifo nosso).

Sendo assim, aposta-se que os Game Studies podem ser usados não apenas para discutir o ato de jogar em si, mas também para estudar toda uma "Cultura Gamer" que cerca estas práticas. Neste sentido, o estudo da pirataria em comunidades virtuais pretende investigar o complexo sistema de distribuição e customização de produtos culturais promovido pelas associações coletivas de usuários e objetos técnicos. Observa-se que as parcerias e recursos técnicos mobilizados para fins de entretenimento também podem apresentar uma complexidade que exige a utilização de toda a potencialidade do processo cognitivo. Estes procedimentos de ordem coletiva e criativa seriam parte integrante do entretenimento contemporâneo, pelo menos no caso dos videogames.

Segundo o teórico dos Game Studies, Stuart Moulthrop, "Nos games, a atividade cognitiva fundamental não é interpretar, mas configurar, a capacidade de transformar certos aspectos de um ambiente virtual com consequências potencialmente relevantes para o sistema como um todo".6 (MOULTHROP, 2004, p. 60, tradução nossa). Ou seja, a "lógica configurativa" de Moulthrop destaca o que ele considera a característica central do meio,

${ }^{6}$ Do original: "in games the primary cognitive activity is not interpretation but configuration, the capacity to transform certain aspects of the virtual environment with potentially significant consequences for the system as a whole". 
sua interatividade. Interatividade, assim, não seria apenas uma qualidade dos games, ela seria a característica que os define por excelência (ao lado de sua ludicidade, claro).

Nos termos desta pesquisa, isso significa que existem produtos culturais, não necessariamente games ${ }^{7}$, estimulando a cognição humana apenas por sua própria complexidade - de tal forma que um indivíduo quase precise quebrar/decodificá-lo para assistir, ler ou jogá-lo (REGIS et al., 2009). E esse fluxo de produtos culturais, não limitado às mídias digitais, pode ter um papel no desenvolvimento de habilidades cognitivas específicas (aquelas que devem promover e requerer o tipo de pirataria estudado aqui).

Cabe ressaltar que é um entendimento amplo da chamada lógica configurativa que serve de mote a esta pesquisa. Acredita-se que, na contemporaneidade, a disseminação do jogar e sua lógica, inclusive para outros meios de comunicação, seria um elemento que revelaria certa "materialidade" do entretenimento digital que perpassa a noção dos sentidos, mas que produz uma demanda por interatividade - traduzida, neste estudo, também por uma demanda por individualização ou personalização - e experiências lúdicas da ordem dos afetos e das sociabilidades. Por esse motivo, continuando com Moulthrop,

Ao concebermos a configuração como uma forma de envolver não apenas os elementos imediatos, mas também as condições sociais e materiais do game - e por extensão, as condições de outros sistemas regrados como trabalho e cidadania - pode ser muito importante insistir na diferença entre jogar e interpretar, o melhor para resistir à imersão. Qualquer análogo do letramento para mídias interativas precisaria incluir tal resistência. ${ }^{8}$ (MOULTHROP, 2004, p. 66, tradução nossa).

Assim, pensando numa possibilidade de letramento midiático que contemple a configuração como principal característica, os videogames parecem o modelo ideal para uma proposta que expanda essa lógica para abarcar as práticas de customização e personalização tais como as que iremos descrever. Não se trata de inventar uma nova mídia, linguagem ou ainda estabelecer uma ordem de importância de uma sobre outra (da "nova" sobre a "velha), mas apenas apresentar uma perspectiva que trate da forma como os videogames estariam não só remediando outras mídias, como também nossa relação com elas. Sua pervasividade indicaria um paradigma tecnológico (material), que evocaria esse letramento não imersivo ou não interpretativo de que Moulthrop (2004) fala, que é, ao mesmo tempo, afetivo e social (intagível), sendo representado tanto pelas ações piratas

\footnotetext{
7 Anonimizado.

${ }^{8}$ Do original: "If we conceive of configuration as a way of engaging not just immediate game elements, but also the game's social and material conditions - and by extension, the conditions of other rule-systems such as work and citizenship -- then it may be very important to insist upon the difference between play and interpretation, the better to resist immersion. Any analogue of literacy for interactive media would probably need to encompass such resistance".
} 
como por formas menos "subversivas", como a introdução de jogos eletrônicos em sala de aula como complemento ao ensino, o treinamento de médicos em games e/ou simuladores, ou os games que dependem de conexão com redes sociais, extração de metadados e outros tipos de identificação, seja pra conteúdos extras ou imbutidos na mecânica do jogo. Este cenário nos autorizaria a afirmar que um determinado jogador procurará por uma experiência customizada sempre que possível, mesmo que não lhe seja permitido, e que essa lógica tem potencial para transcender o chamado "mundo virtual". Ou, nas palavras do pesquisador e designer Eric Zimmerman, "No próximo século, a maneira que vivemos e aprendemos, trabalhos e relaxamos, nos comunicamos e criamos, vai se parecer cada vez mais e mais com a forma com que jogamos games"9. (ZIMMERMAN, 2009, p. 30).

\section{Entretenimento e multidão: a pirataria como arma dos pobres}

Tomando Aristóteles (2005) como referência, na sociedade grega instava-se que o trabalho físico (braçal) fosse relegado aos escravos, deixando aos cidadãos os prazeres do ócio criativo e a importante função do trabalho intelectual (a política e a filosofia), sobretudo aos filósofos, que estariam acima dos demais. Como a história e o pensamento filosófico mostraram, o ócio, o lazer e o entretenimento também podem ser reconfigurados para fins de produção, um exemplo atual sendo o tempo gasto em redes sociais, que serve para criação de valores (tangíveis e intangíveis) para as empresas detentoras desses serviços. No entanto, uma vez que o trabalho passa a abarcar aspectos culturais, sociais etc., alem dos econômicos, a própria natureza desses interesses faz com que eles constantemente fujam ao controle, dando origem a novos polos de resistência.

Os elementos materiais que fazem parte do processo informacional e de entretenimento (TV por assinatura, dispositivos tecnológicos, conexão banda larga etc.) a princípio parecem estar ao alcance apenas de uma parte dos indivíduos, aqueles que possuem os meios de custear todo esse processo. Dessa forma, os pobres ${ }^{10}$ estariam relegados a uma posição subalterna dentro das hierarquias criadas pelo poder. Negri e Hardt (2010), por exemplo, se utilizam de uma diferenciação orquestrada por Robert Reich

\footnotetext{
${ }^{9}$ Do original: "In the coming century, the way we live and learn, work and relax, communicate and create, will more and more resemble how we play games".

${ }^{10}$ Embora, em termos filosóficos, Negri e Hardt utilizem o termo pobre como forma de qualificar a condição dos indivíduos na Multidão, eles não o desassociam completamente de seu uso corrente. Ou seja, assim como todos somos pobres por nossa posição dentro do Império, os carentes, os subempregados e os miseráveis ainda devem ser considerados em sua condição socioeconômica. Não se deve creditar a teorização proposta pelos autores uma espécie de planificação socioeconômica que ignoraria as desigualdades sociais e de renda ou, na direção oposta, uma glorificação ou defesa da pobreza como modo ideal de vida.
} 
que, acreditamos, seja adequada ao cenário que se pretende advogar em seguida. Segundo eles:

[Reich] reconhece, entretanto, que o crescimento do número desses empregos de manuseio simbólico criativo, baseados no conhecimento, implica um crescimento correspondente do numero de empregos de baixo valor e pouca qualificação no manuseio rotineiro de símbolos, como arquivamento de dados e processamento de textos. Aqui começa a surgir uma divisão de trabalho fundamental na esfera da produção imaterial. (NEGRI; HARDT, 2010, p. 312-313).

Isso significa que um caixa de supermercados se relaciona com bancos de dados, cotações variáveis, códigos mnemônicos, grandes volumes de informação e relações sociais estressantes tanto quanto um corretor da bolsa, no entanto, mesmo que os processos laborais "concretos" tendam a ser cada vez mais semelhantes, eles ainda ocupam lugares diferentes dentro da produção social. E, isso, claro, se referindo a duas classes assalariadas.

Em um mundo em que as exigências do trabalho se confundem independentemente da atribuição, os pobres, como a parte da multidão que lida diretamente com a precariedade material, também estão sujeitos a sua "condição de existência e atividade criativa" comum. E isso independe de seu status empregatício. De acordo com Negri e Hardt (2005):

Os pobres, os desempregados e os subempregados de nossas sociedades estão na realidade ativos na produção social, mesmo quando não ocupam uma posição assalariada [...] As próprias estratégias de sobrevivência frequentemente exigem extraordinária habilidade e criatividade. (NEGRI; HARDT, 2005, p. 178).

Estudos em comunicação sobre a cultura do tecnobrega ${ }^{11}$, estilo musical proveniente das regiões Norte e Nordeste do Brasil, defendem, por exemplo, que é justamente o mercado informal de CDs e DVDs que fomenta a popularização do gênero. 0 tecnobrega gera rendas para a indústria musical e ganha forte repercussão midiática, com diversos artistas considerados "regionais" sendo catapultados ao estrelato nacional (e até internacional) por sua exposição constante nas redes e na TV. Ao mesmo tempo, sua base de fãs é construída (e se expande) com base na circulação livre (e ilegal) de conteúdo, a qual sustenta também os artistas "menores".

Retomando um argumento spinozista apresentando por Negri e Hardt em Commonwealth (2009), poderia se dizer que este e outros exemplos em que o entretenimento é um elemento central evidenciariam, ao contrário do que se pretende

\footnotetext{
11 Podem ser citados o livro Tecnobrega: o Pará reinventando o negócio da música, de Ronaldo Lemos e Oona Castro (2008), e o trabalho de Ana Elena Domb Krauskopf (2009), pesquisadora costa-riquenha do MIT que foi orientada pelo pesquisador da transmídia Henry Jenkins.
} 
defender aqui, que esses fãs, essa multidão dotada de afetos e relações sociais complexas, na verdade estaria lutando por sua servidão (ao entretenimento, ao biopoder). Para os autores,

[...] as ações espontâneas de uma multidão de pessoas, como dissemos, não são necessariamente antissistêmicas ou orientadas em direção à liberação. Na verdade, segundo Spinoza, as pessoas frequentemente lutam por sua servidão como se ela fosse sua salvação. ${ }^{12}$ (NEGRI; HARDT, 2009, p. 190, tradução nossa).

Em uma explanação sobre a natureza do amor, os escritores apresentam sua hipótese de que ele seria a base do comum e da luta pela liberdade, todavia, em casos como o apresentado acima, haveria uma corrupção, um desvio, do amor. Eles esclarecem:

Considere a ignorância, o medo e a superstição, então, não apenas como a falta de inteligência, mas como o poder da inteligência virado contra si mesmo, e igualmente o poder do corpo distorcido e bloqueado. E como o amor é, em última análise, o poder da criação do comum, o mal é a dissolução do comum.13 (NEGRI; HARDT, 2009, p. 193, tradução nossa).

Sendo inegável sua ligação com as corporações transnacionais e a valoração do capital, o entretenimento, em relação ao amor e ao comum, a priori não se mostra muito receptivo aos fins revolucionários. Lembrando que o próprio mercado vem instigando seus consumidores a "personalizarem" sua experiência como forma de mantê-los presos, seja a um provedor de internet, a uma operadora de telefonia celular, uma cadeia de fast-food, um banco, entre outros serviços.

Geralmente, quando um consumidor é apresentado ao seu "direito" de pagar apenas pelos aplicativos que lhe interessam no aparelho celular, escolher os ingredientes de sua refeição, comprar de forma independente as músicas de um álbum e assim por diante, ele não está exercendo sua liberdade, mas apenas sendo envolvido na produção biopolítica do capital. A forma como o capitalismo apropriou essa tendência - muitas vezes institucionalizando o encarecimento de produtos como ônus "natural" desta "maior liberdade" - atesta um sistema de exploração baseado nos afetos. Daí Negri e Hardt (2010) afirmarem que:

As grandes potências industriais e financeiras produzem, desse modo, não apenas mercadorias mas também subjetividades. Produzem subjetividades agenciais dentro do contexto biopolítico: produzem necessidades, relações sociais, corpos e mentes - ou seja, produzem produtores. Na esfera

\footnotetext{
12 Do original: "the spontaneous actions of a multitude of people, as we said, are not necessarily antisystemic or oriented toward liberation. In fact people often struggle for their servitude, as Spinoza says, as if it were their salvation".

${ }^{13}$ Do original: "Consider ignorance, fear, and superstition, then, not just as the lack of intelligence but as the power of intelligence turned against itself, and equally the power of the body distorted and blocked. And since love is ultimately the power of the creation of the common, evil is the dissolution of the common".
} 
biopolítica, a vida é levada a trabalhar para a produção e a produção é levada a trabalhar para a vida. (NEGRI; HARDT, 2010, p. 51).

Esses movimentos, contudo, levam a formas mais radicais de libertação, como os próprios autores advertem. Sempre que uma contrainsurgência encontra um meio de "alcançar" a inovação promovida no seio da coletividade, a criatividade a que Negri e Hardt se refere já está se manifestando de maneira diferente. Assim:

Cada nova forma de resistência destina-se a atacar as qualidades antidemocráticas das formas anteriores, criando uma cadeia de movimentos cada vez mais democráticos. [...] essa genealogia de guerras de libertação e movimentos de resistência permitir-nos-á identificar a forma mais adequada de organização para a resistência e as lutas de libertação na situação material e política contemporânea. (NEGRI; HARDT, 2005, p. 103).

Certamente associar iniciativas claramente inseridas dentro do ciclo de consumo capitalista - especialmente a vertente do entretenimento sobre a qual este estudo se debruça, o entretenimento de massa e digital - com o despertar de um potencial afetivo e social da multidão pode parecer um tanto quanto contraditório. Mas, consideradas em si, elas podem ser a porta de entrada para novas organizações de resistência política. Falando especificamente das ações piratas, é possível ver que o próprio Deleuze acredita em seu potencial subversivo. Para o filósofo (2008),

[...] mesmo antes das sociedades de controle terem efetivamente se organizado, as formas de delinquência ou de resistência (dois casos distintos) também aparecem. Por exemplo, a pirataria ou o vírus de computador, que substituirão as greves e o que no século XIX se chamava de "sabotagem" (o tamanco - sabot - emperrando a máquina). (DELEUZE, 2008, p. 216-217).

Entende-se que a pirataria faria parte de um "devir revolucionário" (DELEUZE, 2008, p.211), uma espécie de pulsão em busca de uma maior liberação e mudança do status vigente. Transportando esta fala para o contexto atual, é possível sugerir até um devirpirata, ou melhor, um devir-hacker ${ }^{14}$ da contemporaneidade, o qual, então, surgiria da aliança entre o tecnológico, o político e o entretenimento. Sob o ponto de vista político, acredita-se que esta busca por acessibilidade e uma demanda cultural dentro do capitalismo cognitivo poderiam representar uma ruptura dentro e contra o Império, proporcionando o surgimento de afetos ligados à capacitação cognitiva e tecnológica. E é dentro deste contexto teórico-metodológico maior que se insere a pirataria enquanto fenômeno "concreto", seja a

\footnotetext{
14 Castells (2003), a partir do pensamento de Steven Levy, define o hackerismo como diferentes tipos de "programação criativa". Uma noção um tanto quanto genérica, mas que nos parece ideal para as pretensões teórico-metodológicas deste estudo. Daí a opção, neste momento, por devir-hacker ao invés de um devir-pirata.
} 
tão condenada pirataria "comercial" do camelô, ou o ato caseiro de baixar uma música ou filme para uso próprio. Independentemente de suas implicações éticas, a pirataria representaria uma transformação das dinâmicas produtivas.

Não afirmamos que a pirataria é um fenômeno novo, longe disso, apenas que a mudança de paradigma criada pelo surgimento da cultura digital potencializou (e, claro, pluralizou) o surgimento de práticas inovadoras. Como se essa força de libertação contagiasse as modalidades de produção de subjetividade. E a capacitação cognitiva promovida pelas tecnologias (objetos e técnicas) resultaria em associações criativas e coletivas dentro e fora do ambiente virtual. Assim, ao estudar as interações das comunidades virtuais de compartilhamento e customização busca-se apontar o potencial libertário de ações que são intrinsecamente voltadas para o entretenimento.

Lembrando sempre que a mobilidade exigida no Império cria uma situação de “inclusão diferenciada" (NEGRI; HARDT, 2005, p. 181) com relação àqueles submetidos aos regimes de precariedade e exceção mais agudos - fundamentalmente, os pobres -, os quais também se encontram arrolados nos processos de informatização da produção, afetos e serviços, só que dentro de uma lógica própria marcada pela escassez (de recursos, de instrução, de oportunidades), dessa forma eles são "incluídos enquanto excluídos". É justamente essa condição que, afirmamos, os coloca na vanguarda da resistência ao e no entretenimento. Adotando mais uma vez o esquema positivo spinozista, Negri e Hardt (2009) dizem que "[...] a luta pela liberdade e pelo comum reside no nível mais básico da vida; depois o desejo coloca em ação a construção do comum; e finalmente o amor consolida as instituições do comum que formam a sociedade".15 (NEGRI; HARDT, 2009, p. 193, tradução nossa).

Sendo assim, em meio a este cenário conturbado de informatização e produção (e manipulação) de afetos, os pobres ${ }^{16}$, ávidos por ter acesso pleno às potencialidades da cultura digital e do entretenimento, encontram maneiras criativas e sociais de perseguir seu desejo por meio da pirataria. Pretende-se, desta forma, uma analogia entre a condição de vida do migrante e do desejo de lazer e entretenimento, com foi exposto pelos autores:

[...] os movimentos migratórios são movidos pela necessidade de escapar de condições de violência, fome ou privação, mas paralelamente a essa condição negativa existe também o desejo positivo de riqueza, paz e

\footnotetext{
15 Do original: "[...] the striving toward freedom and the common resides at the most basic level of life; then desire sets in motion the construction of the common; and finally love consolidates the common institutions that form society".

${ }^{16}$ Finalmente, pode se dizer que o pobre objeto deste estudo, para além das concepções filosóficas negrianas, é também todo aquele que se encontra à margem, sobretudo socioeconomicamente, mas também geograficamente, educacionalmente, politicamente, tecnologicamente, entre outros fatores.
} 
liberdade. Esse duplo ato de recusa e expressão de desejo é de uma força extraordinária. (NEGRI; HARDT, 2005, p. 181, grifos nossos).

Daí a incitação por acesso e participação na cultura, na educação, na política e no entretenimento que abarca a multidão como um todo. Hoje em dia, há diversos grupos dedicados a legendar produções audiovisuais (fansubers), traduzir histórias em quadrinhos e livros (scanlators) e, claro, redistribuir e organizar toda essa produção. 0 que, nesta proposta, representaria o início de uma tomada dos meios de produção ligados ao entretenimento, uma reestruturação dos locais de fala e da produção cultural.

No universo dos games, essa intervenção hacker também não se resume a distribuição alternativa de conteúdo, mas também a sua manipulação constante, muitas vezes requerendo de usuários sem nenhum treinamento formal aptidões técnicas (semi) profissionais. Cria-se, então, um regime de autoformação com base no compartilhamento de dados e tutoriais, no qual os próprios usuários se instruem a produzir novos conteúdos, "remixando" materiais originais - por meio da volatilidade do meio digital - e impingindo suas próprias subjetividades a esses produtos.

\section{Life is a game we play}

Dentro deste contexto, esta proposta exploratória pretende analisar o funcionamento da comunidade "Brazukas" da extinta rede social Orkut ${ }^{17}$. As comunidades do Orkut eram basicamente fóruns de discussão (do inglês, message board) acoplados a rede social. Então, como método de pesquisa, utilizou-se a observação participativa dessas comunidades na função de "usuário logado", se filiando a comunidade sempre que necessário. É importante frisar que sem uma conta na rede social boa parte do conteúdo não fica visível ${ }^{18}$. Para os perfis particulares visitados optou-se por não adicionar e apenas colher o máximo possível de informação sem ser amigo do usuário. Além de este artigo ser ainda uma pesquisa exploratória, queria-se observar justamente quanta informação pessoal se pode adquirir desta forma.

Os Brazukas se dedicam ao game de futebol Pro Evolution Soccer (PES) da empresa japonesa Konami. Tendo sido criada em 2001, a franquia Pro Evolution Soccer (Winning

\footnotetext{
${ }^{17}$ Após anos perdendo popularidade para o Facebook, o Orkut foi oficialmente descontinuado por sua mantenedora, a Google Inc., em setembro de 2014 . 0 presente texto, no entanto, foi feito com base numa análise empregada em 2013 quando ainda era possível acessar as comunidades.

${ }^{18}$ Num acesso sem estar logado, ao invés aparecer a página inicial do Orkut para que se efetue o login, é possível, por exemplo, ver diretamente a página de uma comunidade, só que sem os tópicos ou até mesmo ela toda. Ou seja, também há níveis de visualização dependendo da política de privacidade adotada pelo perfil e/ou comunidade.
} 
Eleven 5, no Japão) tem como precursor o jogo Goal Storm/World Soccer Winning Eleven, de 1996. O PES, como é comumente chamado, atingiu popularidade internacional e hoje divide o mercado mundial de jogos de futebol com o game FIFA, da norte-americana Eletronic Arts (EA). Por questões contratuais, a série não possui boa parte das licenças para utilizar nomes e emblemas dos times de futebol, assim, em casos como o do campeonato inglês, os times possuem nomes genéricos para driblar esta proibição (Manchester City, por exemplo, vira Manblue). Além disso, algumas edições não possuíam nem ao menos a versão genérica do campeonato, como o Brasileirão ou a Bundesliga, o campeonato alemão. Acredita-se que estes sejam os grandes motivadores de algumas das práticas que este artigo procurará descrever.

0 "Brazukas" é uma equipe dedica à produção de patches (do inglês, remendos) que servem, no caso deles, apenas para serem inseridos na versão para computador do PES. Patches são arquivos piratas que modificam o conteúdo original do jogo complementando alguma característica que ele não possua. Não foi possível precisar se o grupo nasceu mesmo no Orkut ou em outra plataforma, mas observou-se que pelo menos seus moderadores ${ }^{19}$ são de diferentes estados do Brasil - com exceção de um, eles se identificam como residentes do Nordeste ou Sudeste. Pelas informações da página inicial da comunidade, sabe-se que ela foi criada em 2007 e que seu dono ${ }^{20}$ a identificou como sendo proveniente de Fortaleza, no Ceará, cidade na qual ele mesmo reside.

A comunidade possui quase 71 mil usuários e se vangloria disso em sua descrição, na qual se lê "a maior e melhor comunidade de patchs [sic] do Brasil". De fato, ela é mesmo a maior comunidade dos grupos fechados encontrada no Orkut, motivo pelo qual foi selecionada para este estudo. Esse fato inclusive contribui para que as iniciativas piratas encontradas na comunidade não se restrinjam a ações dos moderadores. Supõe-se que a quantidade elevada de membros possibilita a realização de mais "conexões" entre usuários e as redes de contatos em que eles se inserem. Constatou-se, por outro lado, uma baixa participação dos usuários moderadores na comunidade, deixando-a basicamente a cargo dos demais membros. Isso se dá, possivelmente, pela postagem do dia 13 de julho de 2012,

\footnotetext{
19 Moderadores são usuários que possuem algum poder de edição no fórum outorgado pelo criador da comunidade. Eles podem excluir tópicos, editar mensagens alterar a descrição da comunidade etc. São curadores encarregados da gestão das comunidades.

${ }^{20}$ No Orkut, o dono da comunidade geralmente é quem a criou. No entanto, caso este usuário cancele sua conta na rede social ou apenas não queira mais participar da comunidade era possível passar ou simplesmente deixar o cargo. Era possível abandonar a comunidade sem que o conteúdo fosse perdido. Aliás, para que isso ocorresse seria necessário acionar o botão "excluir comunidade" e ainda confirmar essa opção numa outra janela. Caso isso não fosse feito, a comunidade apenas ficaria lá esperando que alguém assumisse a posição de dono.
} 
na qual um deles informa que o grupo pretende migrar para o Facebook. De fato, mesmo antes de sua desativação, diversas pesquisas já indicavam que o Orkut tinha sido ultrapassado ${ }^{21}$ pela página de Mark Zuckerberg no número total de usuários. No entanto, até o presente momento (maio de 2014) a comunidade em si foi pouco afetada pela notícia, e o grupo do Facebook, criado no dia 26 de junho de 2012, possui pouco menos de 6200 membros, 12 vezes menos usuários. Presume-se que as características específicas das comunidades do Orkut possam contribuir para a pouca adesão ao novo espaço - além, claro, do relativamente pouco tempo de existência do grupo do Facebook e do fato da página do Orkut já ter um público consolidado²2.

Embora a moderação estivesse em processo de deixar a comunidade, eles ainda respondiam dúvidas e postavam conteúdo. A comunidade funcionava como um fórum de discussão para o seu "blog oficial”, dentro do serviço Blogspot, e não só como repositório de arquivos - como será visto a seguir, esta ação é feita por outros usuários. Os moderadores se encarregavam da criação e manutenção dos "tópicos oficiais" que seriam tópicos precedidos de uma tag (do inglês, marcação), sendo esta uma das ferramentas organizacionais mais importantes da comunidade. As tags são inscrições no título (ou assunto) do tópico que designariam sua função ${ }^{23}$. Essas marcações são feitas em caixa alta e dentro de colchetes, por exemplo, [BATE PAPO] que determinam seções exclusivas para um determinado fim.

Um desses tópicos representa exatamente o motivo pelo qual o grupo Brazukas é considerado, para esta pesquisa, fechado e altamente hierarquizado. Com a tag [ERROS DO PATCH BRAZUKAS MIX], os moderadores concentram o feedback do patch criado por eles. Com uma espécie de Serviço de Atendimento ao Consumidor (SAC), os moderadores utilizam as informações dadas pelos usuários para aperfeiçoar o patch e até respondem algumas dúvidas quanto a sua instalação. Esse nível de organização demonstra como as atividades piratas contemporâneas são complexas, muitas vezes emulando um tipo de estrutura (semi) profissional e/ou corporativa.

Neste sentido, chega a ser curiosa a postagem presente no cabeçalho do "blog oficial" avisando que os usuários não devem compartilhar o conteúdo do blog em outras redes sem autorização ou sem os devidos créditos visando preservar o nome (a marca) e a

\footnotetext{
21 Disponível em: <http://www.cartacapital.com.br/tecnologia/facebook-supera-o-orkut-em-visitantes-unicos-e-lideramercado-de-redes-sociais-no-pais-2/>. Acesso em: 17 maio 2014.

${ }^{22}$ Com o crescimento da comunidade no Facebook que, em julho de 2012, possuía apenas 180 membros e agora possui mais de seis mil, caberia futuramente uma análise comparativa das dinâmicas empregadas nos dois grupos.

23 De um ponto de vista técnico, não é preciso ser moderador para criar um tópico com tag na rede social, mas, hierarquicamente, algumas só podem ser instituídas por eles.
} 
"originalidade" do serviço oferecido por eles. Além disso, também é recomendado que os usuários só instalem em seus computadores patches retirados daquela página - chamados por eles de patches originais - sob o risco de danificar sua versão do jogo, uma vez que o serviço prestado por eles teria um "selo de qualidade". Lembrando que eles não cobram nada por esse serviço e até onde pode ser visto também não pedem doações ${ }^{24}$.

0 último elemento analisado trata justamente da ação de usuários não moderadores na comunidade. Por ser um fórum de discussão criado há alguns anos e com um número considerável de seguidores, foi observado que os usuários de maneira geral possuem bastante autonomia para resolver questões e postar conteúdo. No tópico chamado [BATE PAPO], por exemplo, um usuário identificado como Pablo, que não está presente na lista de moderadores, auxilia um novato com uma dúvida referente a uma versão antiga do jogo. A dúvida, aliás, é bem peculiar, o garoto quer saber como reconstruir o rosto de um atleta que não está no jogo original, nem no patch da equipe. Mesmo não encontrando o tal patch com o rosto do jogador, Pablo indica um tutorial mostrando como realizar a edição facial de um avatar.

Para tal, ele deve usar um programa especifico chamado Game Graphic Studio, tratado como GGS na postagem. Outro fator curioso é que esse tutorial não é escrito, mas se encontra no Youtube. Nele, há um passo a passo da execução da edição mostrada através da captura do que acontece na área de trabalho - o que, cabe ressaltar, necessita de outro programa específico não disponível entre as ferramentas básicas da maioria dos sistemas operacionais. Cria-se, então, uma nova trama sociotécnica de autoformação e tutoria a partir desse espaço de trocas de informações e técnicas, mas, sobretudo, de afetos.

\section{Considerações finais}

Esta pesquisa exploratória buscou analisar as práticas de comunicação ligadas a pirataria de games realizada no país. Constatou-se que os usuários estão de fato envolvidos numa rede colaborativa e inovadora voltada para o entretenimento, mas que também acaba resultando mesmo que indiretamente em certa emancipação dos produtos culturais do sistema capitalista. Proporcionando a produção de afetos e de conhecimento, o livre compartilhamento de informação e o fomento de relações sociais, a pirataria de games (e do entretenimento em geral) pode representar um marco dentro das ações de resistência.

\footnotetext{
${ }^{24}$ É preciso salientar, no entanto, que é possível encontrar em qualquer camelô da cidade (e até do país) uma versão do PES já com um patch instalado. Não foi possível descobrir se esta versão tem alguma ligação com os donos da comunidade ou se é obra de algum outro usuário se apropriando do conteúdo alheio para lucrar.
} 
Seguindo uma tradição de reordenação do cultural e do lúdico para fins políticos, as intervenções dentro do universo gamer - que teriam a interação e o lúdico como princípios básicos - constituem um campo de estudos relevante por seu potencial para expressão da subjetividade.

Não se supõe, no entanto, que essas estratégias sejam restritas aos gamers, podendo ser encontradas em outros nichos de fandom como o musical, televisivo, cinematográfico, entre outros. No entanto, nos games parece que quanto mais pessoal, customizado, participativo o processo, mais o usuário se envolve no ato de jogar. Lembrando que a maioria dos jogos eletrônicos, desde os primórdios, permite algum nível de personalização da experiência: seja apenas nomeando um avatar; identificando os recordes de uma partida com suas inicias, como nos fliperamas; até a recriação total de um personagem segundo a identidade do jogador, como é possível nos jogos atuais.

\section{Referências}

AARSETH, Espen. Cybertext: perspectives on ergodic literature. Baltimore: John Hopkins University, 1997.

ARISTÓTELES. A política. São Paulo: Hemus, 2005.

CASTELLS, Manuel. A galáxia da internet: reflexões sobre a internet, os negócios e a sociedade. Rio de Janeiro: Zahar, 2003.

DELEUZE, Gilles. Foucault. São Paulo: Brasiliense, 2005.

DELEUZE, Gilles. Conversações. São Paulo: Editora 34, 2008.

FOUCAULT, Michel. História da sexualidade I: a vontade de saber. 13. ed. Rio de Janeiro: Edições Graal, 1999.

HENNION, Antoine. Music lovers. taste as performance. Theory, Culture \& Society, London, v.18, n. 5, p. 1-22, 2001.

JENKINS, Henry. Convergence culture. New York: New York University, 2006.

JOHNSON, Steven. Tudo que é ruim é bom para você: como os games e a TV nos tornam mais inteligentes. Rio de Janeiro: Zahar, 2012.

KEEN, Andrew. The cult of the amateur: how today's internet is killing our culture. New York: Doubleday, 2007. 
KRAUSKOPF, Ana Elena Domb. "Fire, lights, everything!": exploring symbolic capital in the tecnobrega dance scene. 2009. Dissertação (Mestrado comparative media studies) Program in Comparative Media Studies do Massachusetts Institute of Technology, San Jose, 2009. Disponível em: <http://cmsw.mit.edu/symbolic-capital-tecnobrega-dance-scene/>. Acesso em: 14 jul. 2015.

LEMOS, Ronaldo, CASTRO, Oona. Tecnobrega: o Pará reinventando o negócio da música. Rio de Janeiro: Aeroplano, 2008.

MOULTHROP, Stuart. From work to play: molecular culture in the time of deadly games. In: WARDRIP-FRUIN, Noah; HARRIGAN, Pat (Org.). First person: new media as story, performance and game. Cambridge: MIT Press, 2004. p.56-70.

NEGRI, Antonio; HARDT, Michael. Commonwealth. Cambridge: Harvard University, 2009.

NEGRI, Antonio; HARDT, Michael. Império. 9. ed. Rio de Janeiro: Record, 2010.

NEGRI, Antonio; HARDT, Michael. Multidão. Rio de Janeiro: Record, 2005.

REGIS, Fátima. Da cultura de massa à cultura ciber: a complexificação da mídia e do entretenimento popular. Revista Interin, Curitiba, v. 7, n. 1, 2009.

REGIS, Fátima. Tecnologias de comunicação, entretenimento e competências cognitivas na cibercultura. Revista Famecos, Porto Alegre, v. 1, n. 37, p. 32-37, 2008.

REGIS, Fátima et al. Tecnologias de comunicação, entretenimento e cognição na cibercultura: uma análise comparativa dos seriados O Incrível Hulk e Heroes. Revista Logos Eletrônica, João Pessoa, v. 17, p. 30-41, 2009.

STEINKUEHLER, Constance; JOHNSON, Barbara Z. Computacional literacy in online games: the social life of mods. International Journal of Gaming and Computer-Mediated Simulations, v 1, n. 1, p. 56-65, jan./mar., 2009.

ZIMMERMAN, Eric. Gaming literacy: game design as a model for literacy in the twenty-first century. In: PERRON, Bernard; WOLF, Mark J. P. The video game theory reader 2 . New York: Routledge, 2009.

\title{
Notes on game piracy in Brazil: (digital) inclusion of the poor and resistance
}

\author{
Abstract \\ The objective of this study is not to advocate on behalf of piracy \\ in an ethical point of view. Although we recognize the relevance \\ of this debate, our analysis will focus on the cognitive bias and \\ the production of subjectivity linked to the pirate practices in \\ Gamer Culture. We argue that the subjectivities involved in
}


commercial game's piracy put in motion sociability networks, self-taught and tutorship processes, manipulation of complex technical devices, in addition to the stimulus to creative and free production. This report of an ongoing investigation studies virtual communities inside the social network Orkut and its Brazukas group.

\section{Keywords}

Entertainment. Piracy. Resistance. Games.

Recebido em 18/05/2014

Aceito em 28/05/2015 